\title{
Modelling age patterns of internal migration at the highest ages
}

\author{
Tom Wilson
}

The University of Melbourne

Address: Melbourne School of Population and Global Health, The University of Melbourne, 207 Bouverie St, Melbourne, Vic 3010, Australia

Email: wilson.t1@unimelb.edu.au

ORCID: http://orcid.org/0000-0001-8812-7556

\begin{abstract}
Model migration age schedules have proved valuable to demographers for a range of applications for over 40 years. The original Rogers-Castro curve has been extended over time to include a retirement curve, a post-retirement curve, and a student peak. With demographic analyses extending to higher age groups than in the past due to population ageing, it is important for the model schedule to faithfully reflect migration patterns at advanced ages. Recent data on internal migration in the nonagenarian and centenarian ages reveals several examples of rising then falling mobility with increasing age. This paper suggests an alternative specification of the post-retirement curve of the model schedule to reflect this pattern. The modified model migration schedule is successfully fitted to example internal migration age patterns from Australia, Canada and the Netherlands. The modified schedule should prove useful in preparing input data for population projections and analyses of migration age patterns extending to the highest ages.
\end{abstract}




\section{Key words}

Model migration schedule; internal migration; population projections; Australia; Canada;

Netherlands 


\section{Introduction}

Age patterns of internal migration have been of interest to researchers for a long time. They describe age-selective population shifts across a country which help shape regional and local population age structures (Hugo and Harris 2011; Wilson 2015). They are closely connected to events across the life course, such as labour force entry, union formation, childbirth, retirement, and widowhood (Bernard, Bell and Charles-Edwards 2014). At the regional and local scales, internal migration age profiles are influenced by factors such as employment opportunities (Bell 1996), migration for education (Wilson 2014), being closer to friends and family (Thomas, Gillespie and Lomax 2019), relocation to high amenity locations (Sander 2011), and at the local level, housing-related moves (Dittgen and Dutreuilh 2005).

Migration intensity age profiles (with intensity referring to either rates or probabilities) form essential inputs to subnational population projections (e.g. Pittenger 1974; Rees 1997), comparative analyses of migration age patterns (e.g. Bernard and Bell 2015), and multiregional life tables (e.g. Raymer and Baffour 2018), amongst other uses. For many applications, particularly the preparation of subnational population projections, migration age patterns are best smoothed to remove noise. Otherwise, noisy migration age patterns observed over a recent period will be included in projection calculations for decades ahead, leading to implausible and sub-optimal results. The conventional approach to smoothing is to fit a parameterised model migration schedule, although some non-parametric methods have also been proposed, such as kernel regression and splines (e.g. Bernard and Bell 2015; Dyrting 2019). The parameterised model schedule is primarily associated with Rogers, Castro and collaborators (Raymer and Rogers 2008; Rogers, Racquillet and Castro 1978; Rogers and Raymer 1999; Rogers and Watkins 1987), though additions or slight modifications have occasionally been made by other researchers (e.g. Congdon 1993; Wilson 2010), and a 
different form of parameterised migration model was proposed independently by Pittenger (1978).

The model migration schedule consists of several constituent functions, with modelled migration obtained as their sum. Thus,

Model migration intensity $=$ childhood curve + labour force curve + retirement curve + post-retirement curve + student peak + constant.

Figure 1 provides an illustration of the existing full model migration schedule and its constituent functions. Nearly all migration patterns include the infant, labour force and constant curves. Retirement, post-retirement and student peak curves are present in only some migration age patterns. Since first being introduced in the late 1970s, the model schedule has been successfully fitted to a wide variety of migration patterns in many countries over many decades (e.g. Bates and Bracken 1987; Hofmeyer 1988; Ishikawa 2001; Liaw and Nagnur 1985; Potrykowska 1988; Rogers 1978; Rogers and Castro 1981; Rogers, Little and Raymer 2010).

[Figure 1 about here]

It is unusual for analyses of migration by age and the application of model migration schedules to extend beyond ages 85 or 90 . But with rapidly growing populations at the very highest ages, particularly in the nonagenarian and centenarian age groups (Robine and Cubaynes 2017; Wilson and Terblanche 2018), there is an increasing need to include these ages in models of migration age patterns and population projections. The existing model migration schedule offers two options for representing migration rates at these ages (Figure 1). A post-retirement curve can be included in which migration rates exponentially increase 
with age, or it can be excluded so that migration intensities at advanced ages follow a flat or slowly declining trajectory with age (Rogers 1988). However, actual patterns of migration at the very highest ages do not always take either of these two forms. As this paper will demonstrate, migration intensities at advanced ages can increase up to a particular high age and then start to decline. An alternative specification of the post-retirement curve in the model migration schedule is proposed to represent this pattern. It is also sensible, from a theoretical perspective, to avoid modelling migration rates which continue to increase exponentially with rising age.

Following this introduction, the next section describes the model migration schedule with the alternative post-retirement curve, and explains how it was fitted. The data for the various case studies are listed in the following section, before some example model migration age schedules are presented for both aggregate and directional internal migration. The final section comprises concluding comments, including strengths and limitations of the modified model schedule.

\section{Model migration schedule}

The alternative specification of the post-retirement curve in the model migration schedule adopts the three-parameter bell-shaped curve proposed by Peristera and Kostaki (2007 p. 147) to model symmetrical fertility age profiles. The same function was used by Wilson (2010) for the retirement curve in place of the traditional double exponential due to parameter instability in the latter when fitting; a similar function was also used to model the retirement curve by Congdon (1993). The three-parameter function is relatively simple, easily interpretable, and stable when fitting with iterative nonlinear algorithms. When applied to represent the postretirement curve, parameter $a_{4}$ determines the height of the curve, $\mu_{4}$ is its modal age, and $\sigma_{4}$ 
the width of the distribution. It is shown in the model migration schedule presented in Figure 2. Conceptually, this post-retirement curve signifies a rise in migration intensity at high ages associated with moves to more appropriate accommodation and care provision and/or housing adjustments following widowhood. At even higher ages migration intensities then decline as those who are going to move have already done so.

[Figure 2 about here]

This alternative function for modelling migration age patterns at the very highest ages prevents migration intensities becoming excessively high in the centenarian ages. It is also quite flexible. In those cases where migration does continue rising with age, parameter $\mu_{4}$ for modal age will be fitted with a value close to very highest age, resulting in a slope of increasing migration intensities up to this very highest age. However, a limitation of adding this alternative post-retirement curve is that the model migration schedule becomes more complex, with the full model comprising 17 parameters.

Algebraically, the model with the alternative post-retirement curve can be written as:

$$
\begin{aligned}
& \widehat{m}(x)=a_{1} \exp \left(-\propto_{1} x\right) \\
& +a_{2} \exp \left\{-\propto_{2}\left(x-\mu_{2}\right)-\exp \left[-\lambda_{2}\left(x-\mu_{2}\right]\right\}\right. \\
& +a_{3} \exp \left[-\left(\frac{x-\mu_{3}}{\sigma_{3}}\right)^{2}\right] \\
& +a_{4} \exp \left[-\left(\frac{x-\mu_{4}}{\sigma_{4}}\right)^{2}\right] \\
& +a_{5} \exp \left\{-\propto_{5}\left(x-\mu_{5}\right)-\exp \left[-\lambda_{5}\left(x-\mu_{5}\right]\right\}\right. \\
& +c
\end{aligned}
$$

where 
$\widehat{m}=$ modelled migration intensity

$x=$ age

$a_{1}=$ height of the childhood curve

$\propto_{1}=$ rate of descent of the childhood curve

$a_{2}=$ height of the labour force curve

$\lambda_{2}=$ rate of ascent of the labour force curve

$\propto_{2}=$ rate of descent of the labour force curve

$\mu_{2}=$ position of the labour force curve on the age axis

$a_{3}=$ height of the retirement curve

$\mu_{3}=$ modal age of the retirement curve

$\sigma_{3}=$ rate of ascent and descent of the retirement curve

$a_{4}=$ height of the post-retirement curve

$\mu_{4}=$ modal age of the post-retirement curve

$\sigma_{4}=$ rate of ascent and descent of the post-retirement curve

$a_{5}=$ height of the student curve

$\mu_{5}=$ position of the student curve on the age axis

$\lambda_{5}=$ rate of ascent of the student curve

$\propto_{5}=$ rate of descent of the student curve

$c=$ constant.

The fitting of model migration schedules presents some challenges because it involves iterative nonlinear regression algorithms which are sensitive to initial parameter values and fail to find a solution in some circumstances (Rogers and Raymer 1999). Although a few fitting programs are available, such as the Stata program by Rogers, Little and Raymer (2010) and the R code by Ruiz-Santacruz and Garcés (2018) and Hunsinger (2019), the case study 
model schedules for this paper were fitted in a Microsoft Excel workbook using VBA code calling Excel Solver. Initially the migration intensities were scaled to sum to unity over all ages so that the initial parameter values for the level of the component curves would not be too far removed from the required values. The fitting process then consisted of two stages.

In the first stage each of the component curves of the model schedule (as shown in Figure 2) was fitted one at a time, following the process in Wilson (2010) and the broad approach set out by Rogers, Castro and Lea (2005). Doing so reduces the chances of the nonlinear fitting algorithms failing or producing implausible parameter values, and it enables some elements of the fitting process to be simplified. Fitting was limited to specified age ranges for each curve with some restrictions on parameters applied to assist with the process. As a default, the childhood curve was fitted over ages 1 to 15 , the labour force curve over ages 16 to 40 (except for the peak student ages), the retirement curve over ages 45 to 75 , the post-retirement curve to ages 75 to 105 , and the student curve to ages 17 to 22 . Variation of these age ranges occurred in some cases to achieve better fits. The constant value was generally set equal to the lowest non-zero migration intensity, and the childhood curve was linearised and fitted by OLS regression. Initial parameter values for the component curves fitted by nonlinear regression were chosen on the basis of previous experience in creating model migration schedules. Adjustments to default initial values were made in some cases to achieve better fits.

In the second stage the parameters were refined by fitting all parameters of the full model schedule simultaneously, taking the parameters from the first stage as initial values. There were no adjustments to parameters applied in this stage. The refining is useful because the separate fitting of curves in stage one involves several approximations, including restrictions placed on some parameters, restricted age ranges used in fitting component curves, and 
overlaps of component curves with those fitted earlier in the process. Finally, the fitted migration intensities were scaled back to their original level.

The Excel workbook for fitting the modified model migration schedule, populated with example migration data, is available on figshare (Wilson 2020). Like all model migration schedule fitting approaches, it is not perfect and can fail to fit some migration age patterns, especially if they are excessively noisy. However, it is quite simple and quick to use, and only requires a basic knowledge of Microsoft Excel.

\section{Data}

Internal migration and relevant population-at-risk data by single years of age up to very high ages for three countries were obtained from relevant national statistical offices. The three case study countries, Australia, Canada and the Netherlands, were selected because of good quality population data at the highest ages, and internal migration and population data available in single year of age detail beyond age 100 . The quality assessment was made by comparing the population-at-risk numbers supplied alongside migration data with advanced age populations estimated by Wilson and Temple (2020) for Australia and population estimates in the Human Mortality Database (2019) for the other countries. Without this assessment it was likely that some population numbers at the highest ages would have been over-estimated, a common problem in countries which use census data as the basis of population estimates (Jdanov, Scholz and Shkolnikov 2005; Thatcher, Kannisto and Andreev 2002), resulting in erroneously understated migration intensities at high ages.

Table 1 summaries the data. Internal migration probabilities were calculated where migration data were observed from the transition perspective, such as that derived from census questions 
on usual address on census night and one year earlier. Probabilities by period-cohort were calculated as probabilities of migration conditional upon survival within the country at census time, which excludes those who emigrated or died during the one-year time interval (Rees, Bell, Duke-Williams and Blake 2000). Standard occurrence/exposure migration rates by age were calculated where the migration data were observed from the movement perspective, such as that collected by a population register or administrative data source. Because of the small numbers of migrants involved, the first set of migration intensities shown in this paper are for aggregate internal migration within a country (i.e. not specific to particular origins and destinations). However, some directional migration flows are just large enough for the patterns at the highest ages to be discernible. Examples from the most populous states in Australia are included.

[Table 1 about here]

Census migration and population-at-risk data for Australia were extracted using the online data extraction tool TableBuilder Pro (ABS 2019) or as customised tables directly from the ABS where the required data was unavailable in TableBuilder. Data for aggregate mobility at three spatial scales was obtained from the 2016 census: (i) all changes of address between census night and one year earlier; (ii) migration between all SA2 areas (2,292 local areas with populations mostly in the range $2,500-25,000)$; and (iii) migration between all SA4 areas (89 larger regions with populations generally between 100,000 and 500,000). In addition, directional interstate in- and out-migration was obtained for New South Wales, Victoria, and Queensland. Because of the small numbers of migrants at the high ages for these directional flows, an average of 2011 and 2016 Census one year interval data was taken. 
For Canada, census migration and population-at-risk data were supplied directly by Statistics Canada. Migration information is collected in the long-form census questionnaire received by $25 \%$ of Canadian households. The scope of the data is restricted to private households only, so moves into institutional accommodation are excluded. Two types of mobility are shown here: (i) all changes of address between census night and one year earlier, and (ii) all moves between census subdivisions (5,162 areas) within the constituent province/territory. For the Netherlands, migration counts and population estimates were obtained from Statistics Netherlands' online data tool Statline (Statistics Netherlands 2019). Data for (i) all moves within municipalities (numbering about 350) and (ii) all migration between municipalities during 2018 were downloaded and used.

For Australia, the census data for females at the highest ages proved to be of good quality, but the male populations are overstated in the centenarian ages, so migration patterns for the female population only are presented. Canadian census data at the highest ages are good quality for both males or females, so migration patterns are shown for persons given that sexspecific numbers at high ages are small. For the Netherlands, official population estimates were found to be in close agreement with those in the HMD for both males and females, so person migration rates are also shown for the Netherlands.

It should be pointed out that, at the highest ages where the volume of migration is limited, migration rates or probabilities have wide confidence intervals. This means that the true underlying migration intensities will vary to some extent from the patterns shown below.

\section{Example internal migration age patterns}




\subsection{Aggregate migration age patterns}

Figure 3 illustrates internal migration probabilities and model migration age schedules for females in Australia for all changes of address, all moves between SA2 areas (local areas), and all migration between SA4 areas (larger regions). The age profiles exhibit features typical of many migration age patterns across the world, including a large peak in the young adult ages followed by declining intensity over much of the adult ages with increasing age, childhood migration rates mirroring those of parents, and an increase in migration in the older age groups. For migration between SA4 areas a student peak is also visible in the late teenage ages, as is some retirement-related migration over ages 55 to 70 .

At the very highest ages, Figure 3 shows a feature of some migration age patterns which is less well known: migration reaches a local peak and then starts to decline. The local peak is more pronounced for all changes of address, which are dominated by short-distance housingrelated moves, than for moves between SA2 and SA4 areas. The share of the Gross

Migraproduction Rate (which is defined as the sum of rates over all ages 1 to 105) contributed by the post-retirement curve is $9.0 \%$ for all moves, $7.2 \%$ for migration between SA2 areas, and $4.4 \%$ for migration between SA4 areas. For all changes of address the modal age of the post-retirement curve $\left(\mu_{4}\right)$ is 99.3 years, age 100.4 for moves between SA2 areas, and age 96.2 for migration between SA4 areas.

The fit of the model migration age schedules is good in terms of both $R^{2}$ measures $(0.997$ for all changes of address and moves between SA2 areas; 0.987 for migration between SA4 areas) and simple visual inspection. Although migration probabilities at the highest ages are quite noisy, the alternative post-retirement curve does a respectable job of modelling the variation in migration at these ages. It is also clear how an exponential post-retirement curve 
would appear to be a good fit to migration age patterns ending at age 85 or 90 . Interestingly, the fit of the model schedule over the childhood ages appears slightly less good due to disruptions to the smooth curve between some ages - perhaps related to the ages at which children start school and switch between primary and secondary schools.

[Figure 3 about here]

Figure 4 shows the migration age patterns for two types of internal migration in Canada: all changes of address, and migration between census subdivisions within provinces/territories. The age pattern for all changes of address follows the form of a classic migration age schedule without any obvious retirement curve. Unlike Australia, there is little difference in levels of mobility above age 70, which may be related to the scope of the data being limited to private households only. Migration between census subdivisions shows much similarity with Australia's migration age profile for SA2 areas up to around age 70. Migration probabilities then continue to decline with age except for a small post-retirement hump in the nonagenarian ages. The fit of both model schedules is good, with the $\mathrm{R}^{2}$ being 0.988 for all changes of address and 0.987 for migration between census subdivisions. For the latter, the fit appears less good over a few teenage age groups, and slightly imperfect over some adult ages.

[Figure 4 about here]

Figure 5 illustrates the migration age patterns and model migration schedules for moves of persons within municipalities, and migration between municipalities, in the Netherlands in 2018. Short-distance within-municipality mobility follows a typical migration age pattern for much of the age range. At the very highest ages there is a substantial post-retirement curve 
which peaks in the nonagenarian ages before falling off rapidly. This curve represents about one sixth (17.3\%) of the Gross Migraproduction Rate between ages 1 and 105. The fit is generally good $\left(\mathrm{R}^{2}=0.992\right)$ except at some high ages where the symmetric shape of the postretirement curve does not fit the migration pattern perfectly. For migration between

municipalities, the model migration schedule provides a good fit over most ages $\left(R^{2}=0.990\right)$, including the highest ages. The post-retirement curve represents about one eighth $(12.1 \%)$ of the Gross Migraproduction Rate.

[Figure 5 about here]

\subsection{Directional migration age patterns}

Figure 6 shows female interstate in- and out-migration age profiles for New South Wales, Victoria, and Queensland based on an average of 2011 and 2016 census migration data. To varying extents all these migration age profiles include a small post-retirement curve with declining migration intensities at the very highest ages, although the pattern is quite noisy at this end of the age profile. The curve appears a little less clear for Victoria. The proportion of the GMR contributed by the post-retirement curve is under $10 \%$ for all age schedules in Figure 6. For New South Wales it is $7.1 \%$ for out-migration and $8.1 \%$ for in-migration; for Victoria just $0.9 \%$ for out-migration and $7.2 \%$ for in-migration; and for Queensland the equivalent shares are $9.6 \%$ and $4.4 \%$. The modal ages of the post-retirement curves are a little lower than in all the aggregate migration age schedules (Figure 3), with all of them lying within the range 88-93 years. Overall, the fit of these model schedules appears good, with $\mathrm{R}^{2}$ values varying between 0.987 and 0.994 .

[Figure 6 about here] 


\section{Discussion and Conclusions}

This paper has proposed an alternative post-retirement curve for the model migration schedule which consists of a bell-shaped curve instead of the traditional exponential function. In the case study countries illustrated above it has proved quite successful in representing internal migration intensities at the highest ages. In doing so the paper has demonstrated that migration intensities do not rise continually with increasing age at the highest ages, at least in the examples shown here. The migration schedules fitted to migration data from Australia and the Netherlands also suggest that post-retirement moves are relatively more important over short distances, which is as expected. It is likely that many of these moves are accommodation-related relocations in which individuals remain within familiar localities. In the Canadian examples, which exclude migration into institutional accommodation, there is less migration at advanced ages but the modified migration schedule still does a good job of representing the recorded migration age patterns.

There are at least three ways in which the modified model migration schedule can be useful. The first is preparing smoothed migration age profiles for population projections which extend to high ages. Population projections and model migration schedules beyond ages 85 or 90 will become increasingly relevant as populations at the highest ages grow rapidly. In Australia, for example, the nonagenarian population grew by $185 \%$ over the two decades to 2018, whilst the number of centenarians increased by 215\% (Wilson and Temple 2020). Importantly, the modified model schedule offers more flexibility in shape at high ages than the exponential function. Many migration age profiles exhibit an increase in migration at high ages followed by a decline, as shown in many of the graphs in this paper. In those cases where migration does continue rising with increasing age, the modified schedule can easily represent 
this pattern; the post-retirement curve will be fitted so that its modal age is close to the highest age in the data. In population projections, the empirical effect of the alternative postretirement curve in place of the traditional curve will be minimal in many cases due to the small size of advanced age populations, but this effect is likely to increase in the future when these populations will be much larger than they are today. Even when the empirical effect is small, it is still good practice to apply model age schedules which represent the underlying pattern of migration.

Second, the modified model schedule as illustrated in Figure 2 presents a simple conceptual model of migration across the life course, with the constituent functions linked to migration motivations and drivers. At the highest ages, migration intensities often increase, representing accommodation-related moves into institutions or to live with family members and housing adjustments following widowhood, but then decline again at higher ages once such moves have been made. This element of the migration age schedule at the highest ages is associated with the 'fourth age' of life in which individuals develop disabilities and require assistance with daily living activities (Rowland 2012).

Third, the model schedule offers a way of comparing underlying internal migration and mobility patterns between countries, both for directional migration and aggregate mobility. As populations at advanced ages continue to expand rapidly, it will be sensible to extend analyses of migration to higher ages. The structure imposed by the model schedule is particularly useful at the highest ages where the pattern of migration intensities is noisy.

The aggregate migration age schedules (Figures 3 to 5) could be useful in comparative analyses of internal migration patterns between spatial scales and between countries. But they 
also have a role to play in supplying surrogate parameters when applying model migration schedules to directional migration age patterns, which will be noisier at the highest ages. In other words, the post-retirement curve at the highest ages is borrowed from more aggregate data and imposed on origin- and destination-specific migration age profiles. Such an approach is analogous to the constrained extrapolation of mortality rates to the very highest ages based on modelling or more robust empirical data (Ediev 2018).

There are, of course, several limitations of the study, and of the proposed version of the model migration schedule. The case study countries in this paper represent a small proportion of all countries, so the assessment of internal migration age patterns in other countries would be valuable in future research. Age patterns of internal migration will vary across the world and may not be precisely modelled by the proposed post-retirement curve. This will be the case if the migration age pattern is markedly asymmetrical at the highest ages given that the function chosen to represent the post-retirement curve is always symmetrical. An alternative function permitting asymmetry could be used instead - but at the cost of adding another parameter to a model which is already quite parameter-heavy.

Model migration schedules have proved a very useful part of the demographer's toolbox since they were introduced by Rogers and colleagues in the 1970s. Over time they have been adapted and extended as their application has expanded and migration age patterns have evolved. The introduction of the alternative post-retirement curve for the very highest ages enables them to cover internal migration patterns spanning the entire human age range, making them well-placed to model the mobility of rapidly growing advanced age populations in the 21 st century. 


\section{Declarations}

\section{Acknowledgements}

The author is grateful to Patrice Dion of Statistics Canada for facilitating access to Canadian census data. Eddie Hunsinger and Sigurd Dyrting kindly provided helpful feedback on an earlier draft. The suggestions of the anonymous reviewers were most helpful.

\section{Funding}

This work was funded by the Australian Research Council's (ARC) Centre of Excellence in Population Ageing Research (CE1101029).

\section{Conflicts of interest/Competing interests}

None.

\section{Code availability (software application or custom code)}

The Excel workbook used to fit the model migration schedule is available at https://doi.org/10.6084/m9.figshare.12415475. The VBA code is available within the workbook. 


\section{References}

ABS. (2019). Australian census data extracted via TableBuilder Pro.

https://www.abs.gov.au/websitedbs/D3310114.nsf/Home/2016\%20TableBuilder.

Accessed 11 August 2019.

Bates, J. and Bracken, I. (1987). Migration age profiles for local authority areas in England, 1971-1981, Environment and Planning A 19, 521-535.

Bell, M. (1996). Understanding Internal Migration. Canberra: Australian Government Publishing Service.

Bernard, A. and Bell, M. (2015). Smoothing internal migration age profiles for comparative research, Demographic Research 32(33), 915-948.

Bernard, A., Bell, M. and Charles-Edwards, E. (2014). Life-course transitions and the age profile of internal migration, Population and Development Review 40(2), 213-239.

Congdon, P. (1993). Graduation in local demographic analysis and projection, Journal of the Royal Statistical Society Series A 156(2), 237-270.

Dittgen, A. and Dutreuilh, C. (2005). Housing and household size in local population dynamics. the example of Paris, Population (English edition) 60(3), 259-298.

Dyrting, S. (2019). Smoothing migration intensities with P-TOPALS, Unpublished manuscript.

Ediev, D. M. (2018). Constrained mortality extrapolation to old age: an empirical assessment, European Journal of Population 34(3), 441-457.

Hofmeyer, B. E. (1988). Application of a mathematical model to South African migration data, 1975-1980, Southern African Journal of Demography 2(1), 24-28.

Hugo, G. and Harris, K. (2011). Population Distribution Effects of Migration in Australia. Report for Department of Immigration and Citizenship. National Centre for Social Applications of GIS, The University of Adelaide. 
Hunsinger, E. (2019). Eddie's R code for fitting the multi-exponential model migration schedule with student peak. Available:

https://applieddemogtoolbox.github.io/Toolbox/\#SPMMSRCode. Accessed 23 September 2019.

Ishikawa, Y. (2001). Migration turnarounds and schedule changes in Japan, Sweden and Canada, Review of Urban and Regional Development Studies 13(1), 20-33.

Jdanov, D. A., Scholz, R. D., and Shkolnikov, V. M. (2005). Official population statistics and the Human Mortality Database estimates of populations aged 80+ in Germany and nine other European countries, Demographic Research 13(14), 335-362.

Liaw, K. and Nagnur, D. N. (1985). Characterization of metropolitan and nonmetropolitan outmigration schedules of the Canadian population system, 1971-1976, Canadian Studies in Population 12(1), 81-102.

Peristera, P. and Kostaki, A. (2007). Modeling fertility in modern populations, Demographic Research 16(6), 141-194.

Pittenger, D. B. (1974). A typology of age-specific net migration rate distributions. Journal of the American Institute of Planners 40(4): 278-283.

Pittenger, D. B. (1978). On making flexible projections of age-specific net migration. Environment and Planning A 10(11): 1253-1272.

Potrykowska, A. (1988). Age patterns and model migration schedules in Poland, Geographia Polonica 54, 63-80.

Raymer, J. and Baffour, B. (2018). Subsequent migration of immigrants within Australia, 1981-2016, Population Research and Policy Review 37, 1053-1077.

Raymer, J. and Rogers, A. (2008). Applying model migration schedules to represent agespecific migration flows. In Raymer, J. and F. Willekens (eds) International Migration in Europe: Data, Models and Estimates. Chichester UK: Wiley; pp. 175-192. 
Rees, P. (1997). Problems and solutions in forecasting geographical populations. Journal of the Australian Population Association 14(2), 145-166.

Rees, P., Bell, M., Duke-Williams, O. and Blake, M. (2000). Problems and solutions in the measurement of migration intensities: Britain and Australia compared, Population Studies 54(2), 207-222.

Robine, J. and Cubaynes, S. (2017). Worldwide demography of centenarians, Mechanisms of Ageing and Development 165, 59-67.

Rogers, A. (1978). Model migration schedules: an application using data for the Soviet Union, Canadian Studies in Population 5, 85-98.

Rogers, A. (1988). Age patterns of elderly migration: an international companion, Demography 25(3), 355-370.

Rogers, A., Little, J. and Raymer, J. (2010). The Indirect Estimation of Migration. Dordrecht: Springer.

Rogers, A. and Castro, L. J. (1981). Model Migration Schedules. Research Report RR-81-30. Laxenburg: International Institute for Applied Systems Analysis.

Rogers, A. and Raymer, J. (1999). Fitting observed demographic rates with the multiexponential model schedule: an assessment of two estimation programs, Review of Urban and Regional Development Studies 11(1), 1-10.

Rogers, A. and Watkins, J. (1987). General versus elderly interstate migration and population redistribution in the United States, Research on Aging 9(4), 483-529.

Rogers, A., Castro, L. J. and Lea, M. (2005). Model migration schedules: three alternative linear estimation methods, Mathematical Population Studies 12(1), 17-38.

Rogers, A., Racquillet, R. and Castro, L. J. (1978). Model migration schedules and their applications, Environment and Planning A 10(5), 475-502.

Rowland, D. T. (2012). Population Aging. Dordrecht: Springer. 
Ruiz-Santacruz, J. S. and Garcés, J. (2018). migraR: prototype package for adjusting Rogers and Castro models. Available: https://github.com/elflacosebas/migraR/ Accessed 23 September 2019.

Sander, N. (2011). Retirement Migration of the Baby Boomers in Australia: Beach, Bush or Busted? PhD thesis, School of Geography, Planning and Environmental Management, The University of Queensland.

Statistics Netherlands. (2019). Internal migration data extracted via the Statline online tool. Available: https://opendata.cbs.nl/statline/\#/CBS/nl/. Accessed 24 September 2019.

Thatcher, R., Kannisto, V., and Andreev, K. (2002). The Survivor Ratio method for estimating numbers at high ages, Demographic Research 6(1): 1-18.

Thomas, M., Gillespie, B., and Lomax, N. (2019). Variations in migration motives over distance. Demographic Research 40(38): 1097-1110.

Wilson, T. (2010). Model migration schedules incorporating student migration peaks, Demographic Research 23.8: 191-222.

Wilson, T. (2014). The impact of education-related mobility on inter-regional migration age profiles in Australia, Applied Spatial Analysis and Policy 8(4): 371-391.

Wilson, T. (2015). The demographic constraints on future population growth in regional Australia, Australian Geographer 46(1): 91-111.

Wilson, T. (2020). Model Migration Schedule fitting example. figshare. Excel workbook. https://doi.org/10.6084/m9.figshare.12415475

Wilson, T. and Temple, J. (2020). More accurate estimates of Australia's population at the highest ages. Manuscript under review.

Wilson, T. and Terblanche, W. (2018). New estimates of Australia's centenarian population, International Journal of Population Data Science 3(1): 1-10. 
Table 1 Summary of case study internal migration data

\begin{tabular}{|c|c|c|c|c|c|}
\hline Country & Migration type & $\begin{array}{l}\text { Migration } \\
\text { intensity }\end{array}$ & Sex & Date & Source \\
\hline \multicolumn{6}{|c|}{ Aggregate migration } \\
\hline Australia & All changes of address & Probabilities & Females & $2015-16$ & 2016 Census \\
\hline Australia & All moves between SA2 areas & Probabilities & Females & $2015-16$ & 2016 Census \\
\hline Australia & All moves between SA4 areas & Probabilities & Females & $2015-16$ & 2016 Census \\
\hline Netherlands & Moves within municipalities & Rates & Persons & 2018 & Population register \\
\hline Netherlands & Moves between municipalities & Rates & Persons & 2018 & Population register \\
\hline Canada & All changes of address & Probabilities & Persons & $2015-16$ & 2016 Census \\
\hline Canada & $\begin{array}{l}\text { All moves between census } \\
\text { subdivisions }\end{array}$ & Probabilities & Persons & $2015-16$ & 2016 Census \\
\hline \multicolumn{6}{|c|}{ Directional migration } \\
\hline Australia & $\begin{array}{l}\text { Out-migration from New South } \\
\text { Wales }\end{array}$ & Probabilities & Females & $\begin{array}{l}2010-11 \& \\
2015-16\end{array}$ & $\begin{array}{l}2011 \text { Census \& } \\
2016 \text { Census }\end{array}$ \\
\hline Australia & $\begin{array}{l}\text { In-migration to New South } \\
\text { Wales }\end{array}$ & Probabilities & Females & $\begin{array}{l}2010-11 \& \\
2015-16\end{array}$ & $\begin{array}{l}2011 \text { Census \& } \\
2016 \text { Census }\end{array}$ \\
\hline Australia & Out-migration from Victoria & Probabilities & Females & $\begin{array}{l}2010-11 \& \\
2015-16\end{array}$ & $\begin{array}{l}2011 \text { Census \& } \\
2016 \text { Census }\end{array}$ \\
\hline Australia & In-migration to Victoria & Probabilities & Females & $\begin{array}{l}2010-11 \& \\
2015-16\end{array}$ & $\begin{array}{l}2011 \text { Census \& } \\
2016 \text { Census }\end{array}$ \\
\hline Australia & $\begin{array}{l}\text { Out-migration from } \\
\text { Queensland }\end{array}$ & Probabilities & Females & $\begin{array}{l}2010-11 \& \\
2015-16\end{array}$ & $\begin{array}{l}2011 \text { Census \& } \\
2016 \text { Census }\end{array}$ \\
\hline Australia & In-migration to Queensland & Probabilities & Females & $\begin{array}{l}2010-11 \& \\
2015-16\end{array}$ & $\begin{array}{l}2011 \text { Census \& } \\
2016 \text { Census }\end{array}$ \\
\hline
\end{tabular}




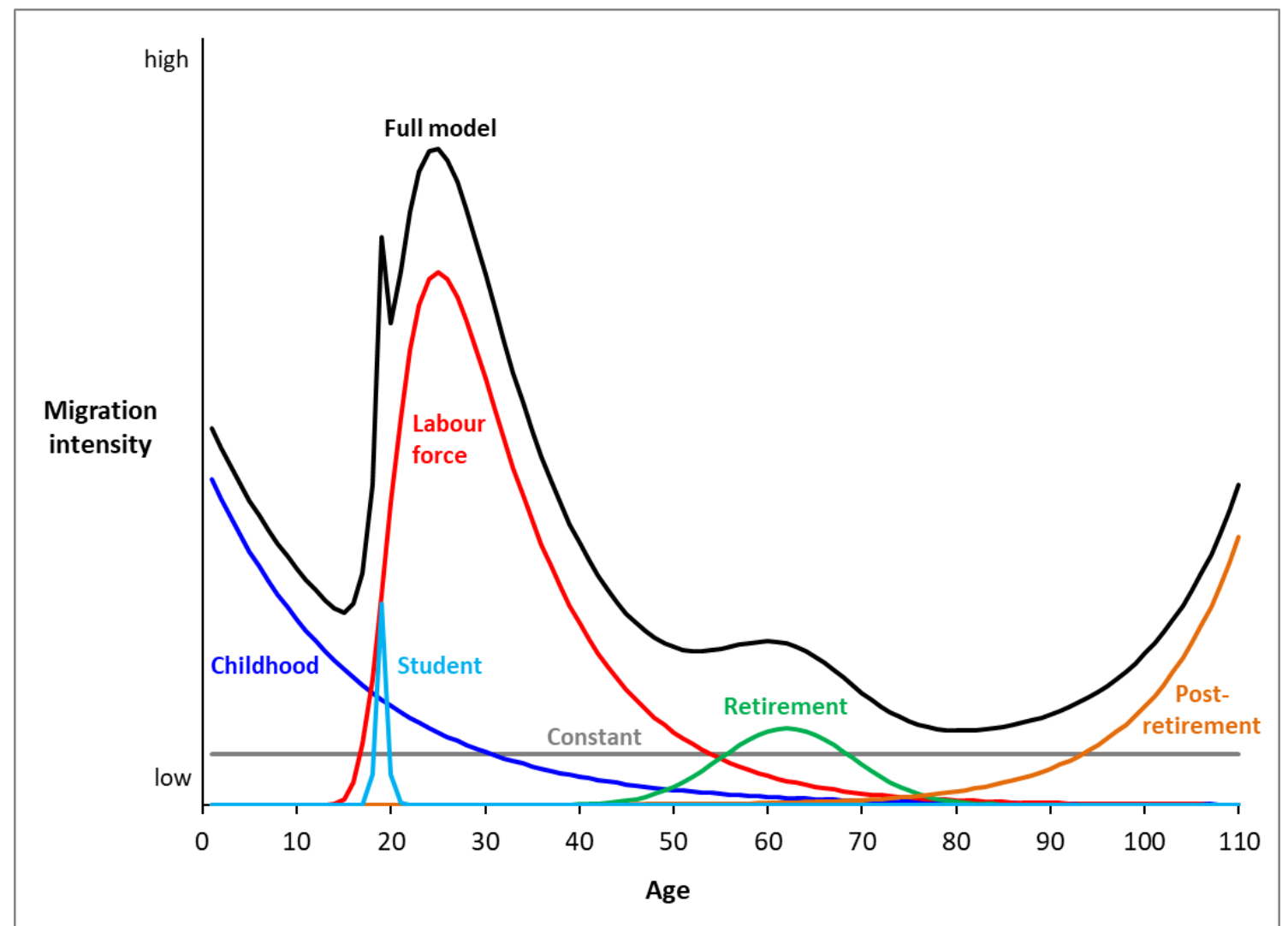

Figure 1 The existing model migration schedule and constituent curves 


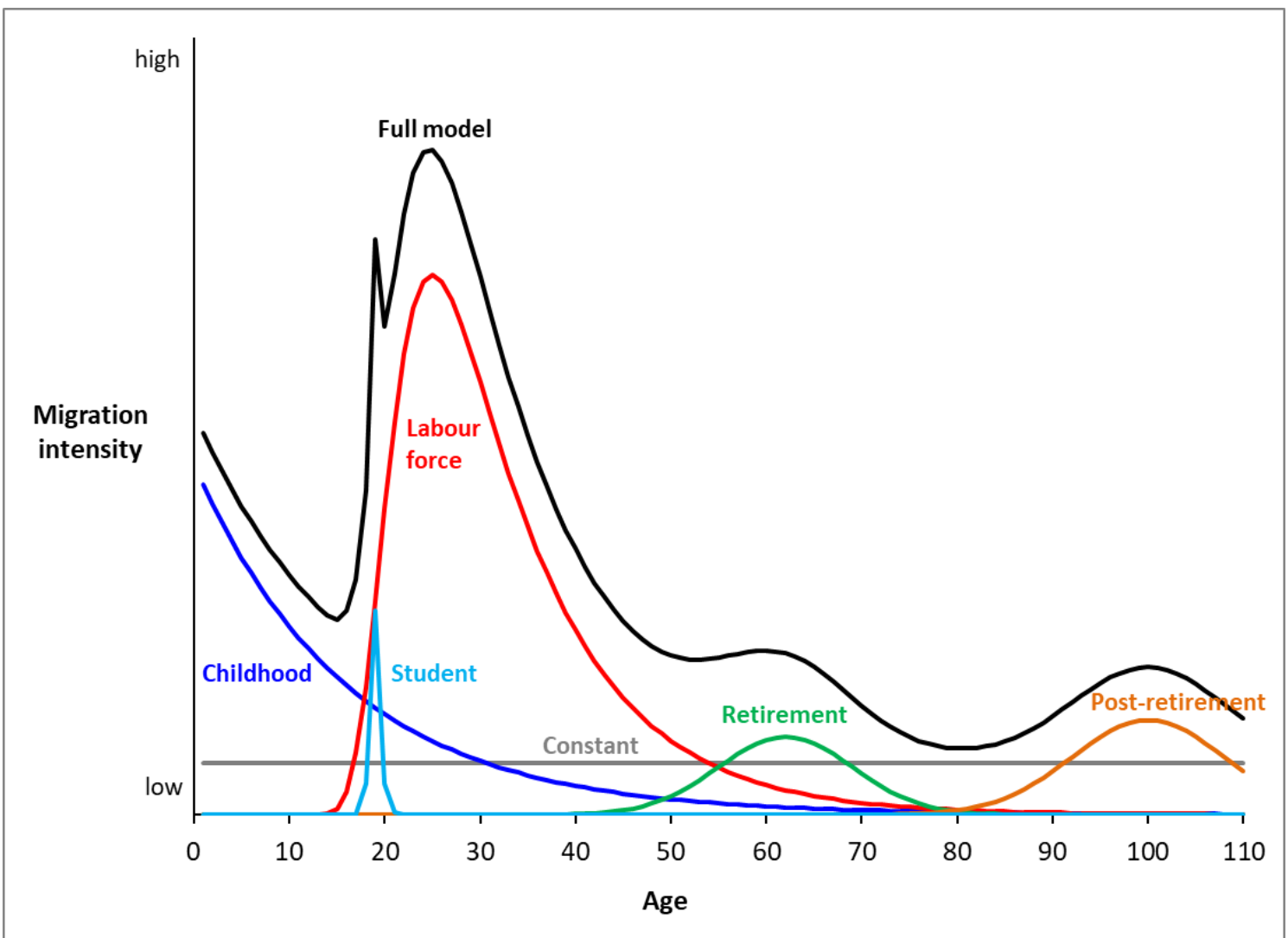

Figure 2 The model migration schedule with the alternative post-retirement curve 

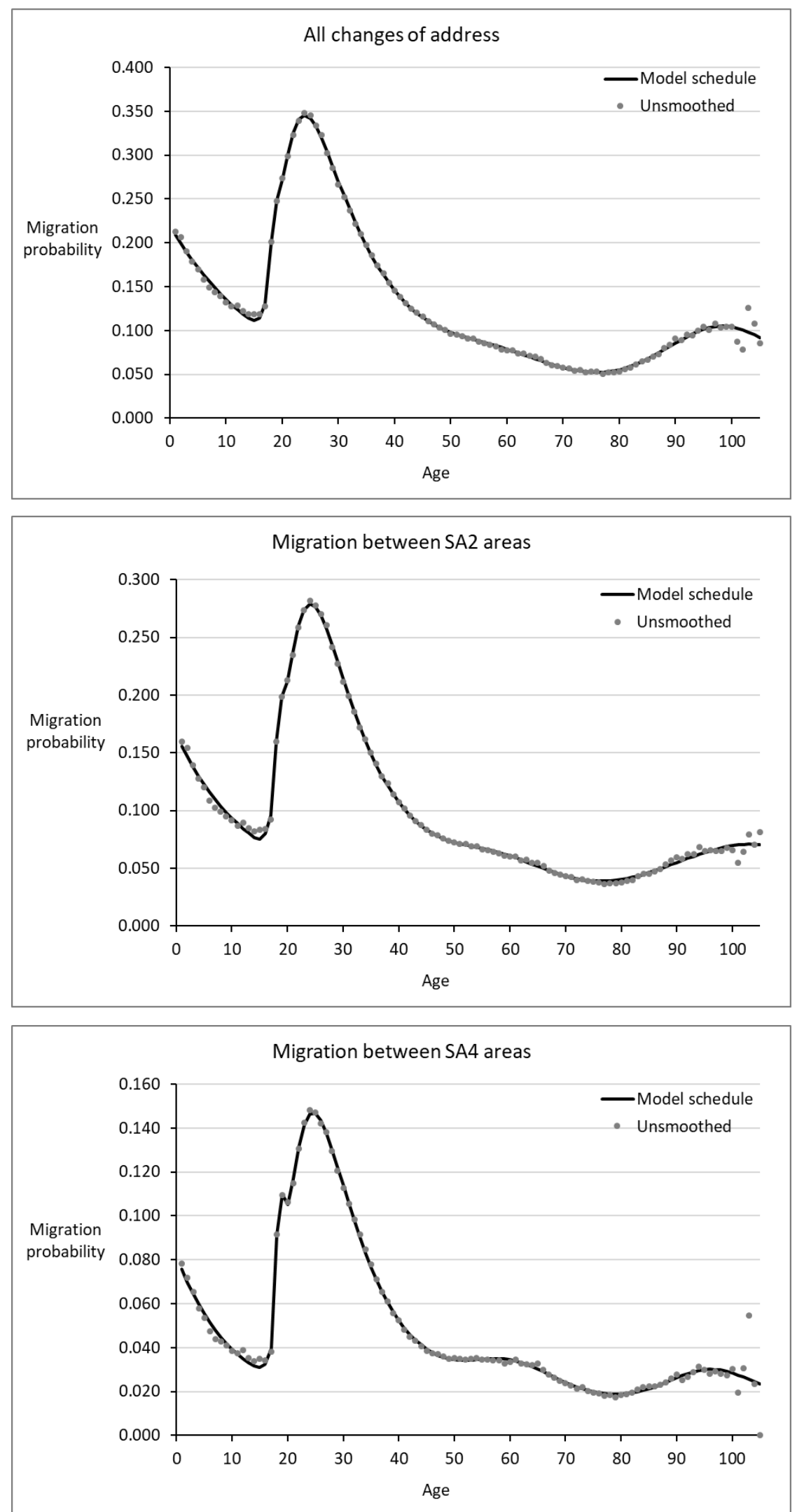

Figure 3 Model migration schedules for internal migration, females, Australia, 2015-16 Source: Author's calculations based on ABS 2016 Census data 

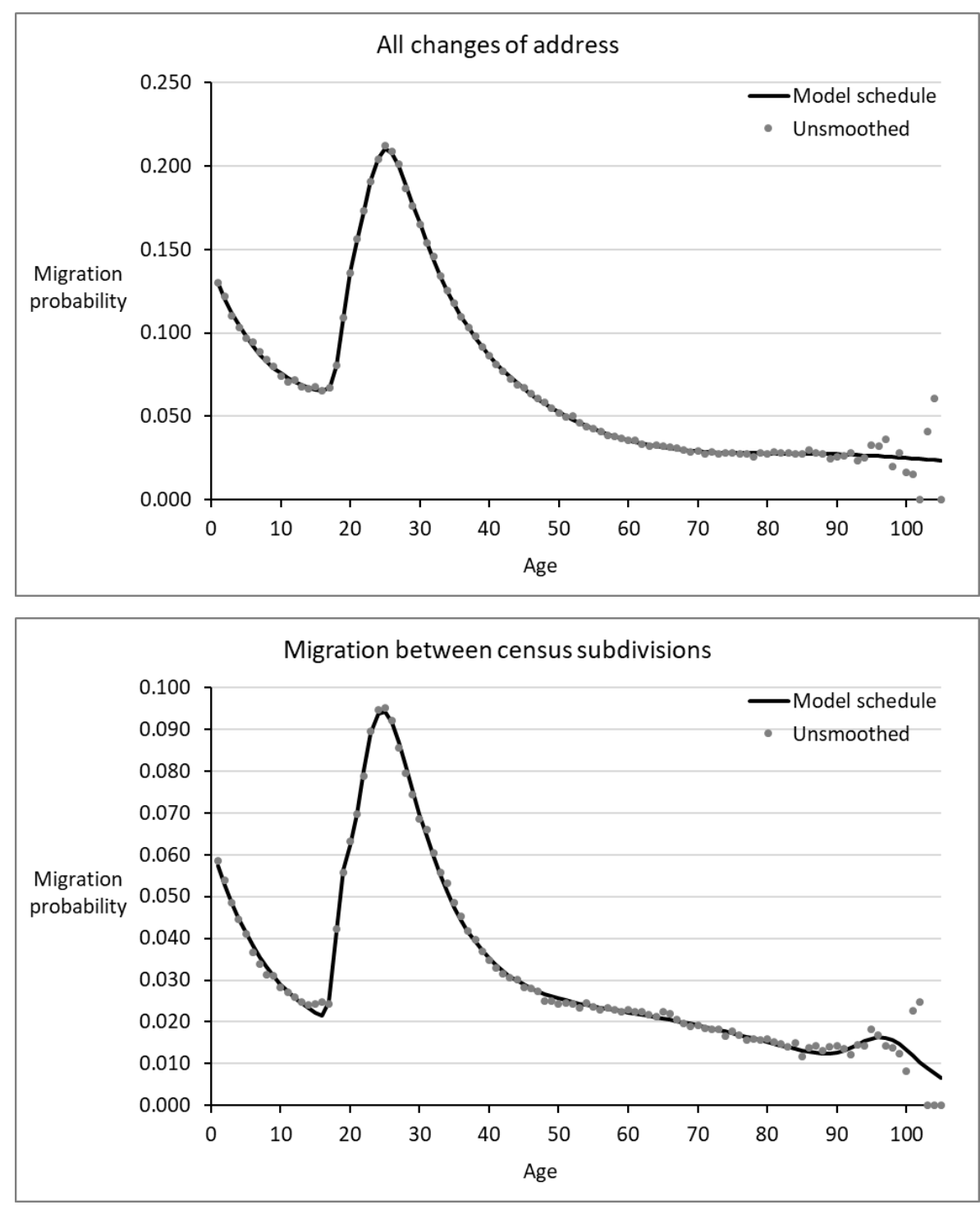

Figure 4 Model migration schedules for internal migration, persons, Canada, 2015-16 Source: Author's calculations based on Statistics Canada 2016 Census data 

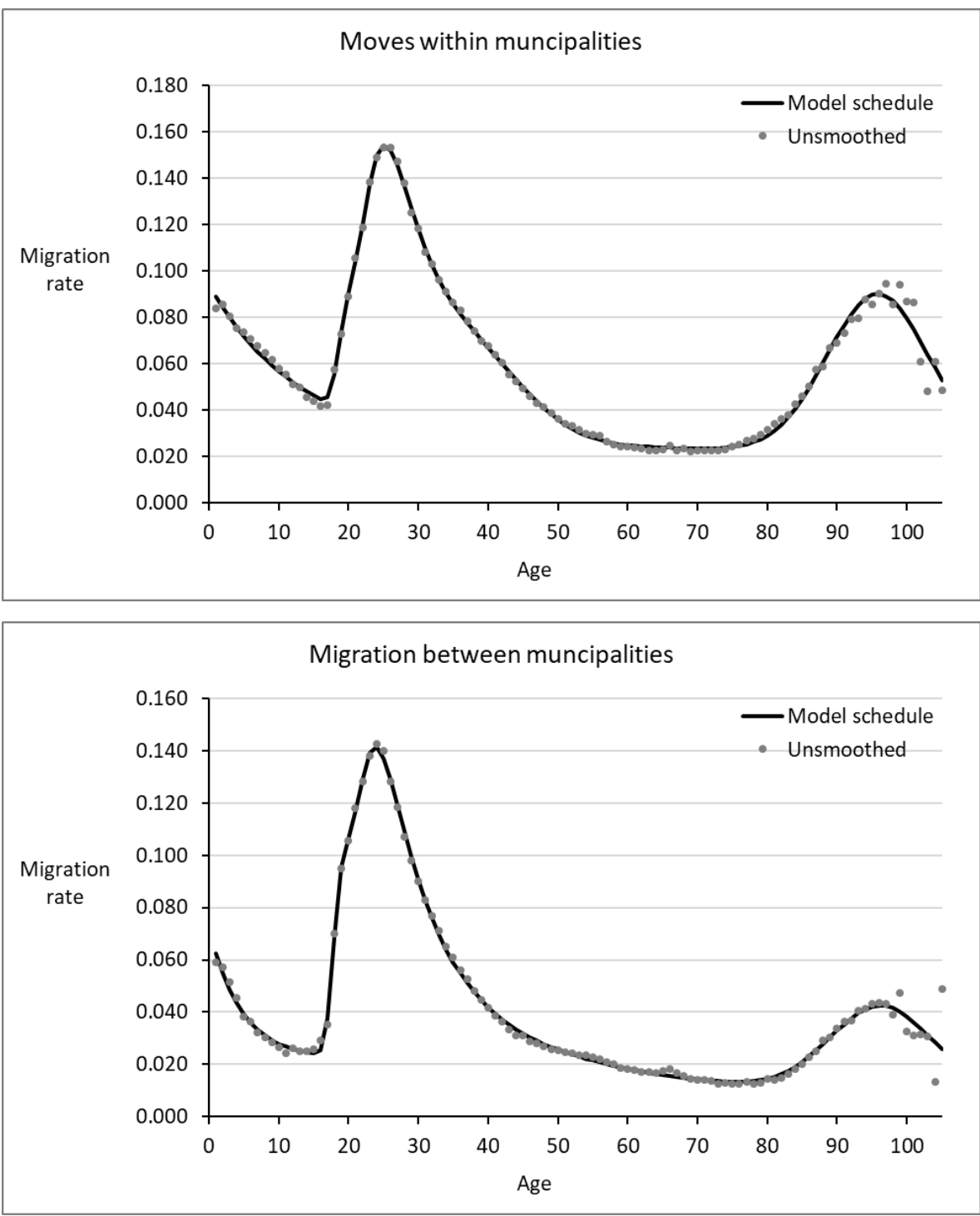

Figure 5 Model migration schedules for internal migration, the Netherlands, persons, 2018 Source: Author's calculations based on Statistics Netherlands 2018 register data 

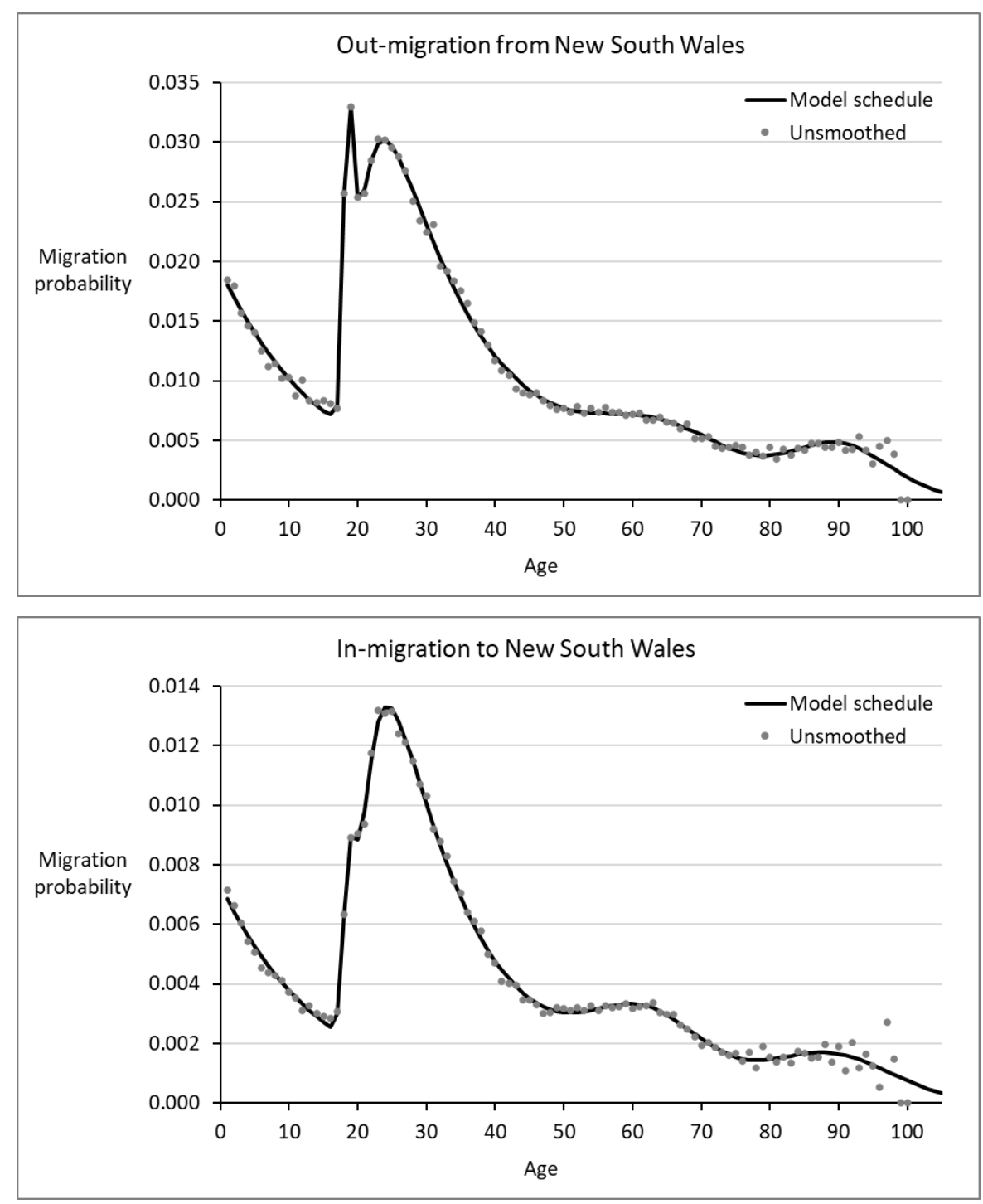

Figure 6 Model migration schedules for directional internal migration, females, Australia, averaged over 2010-11 and 2015-16

Source: Author's calculations based on ABS 2011 and 2016 census data 

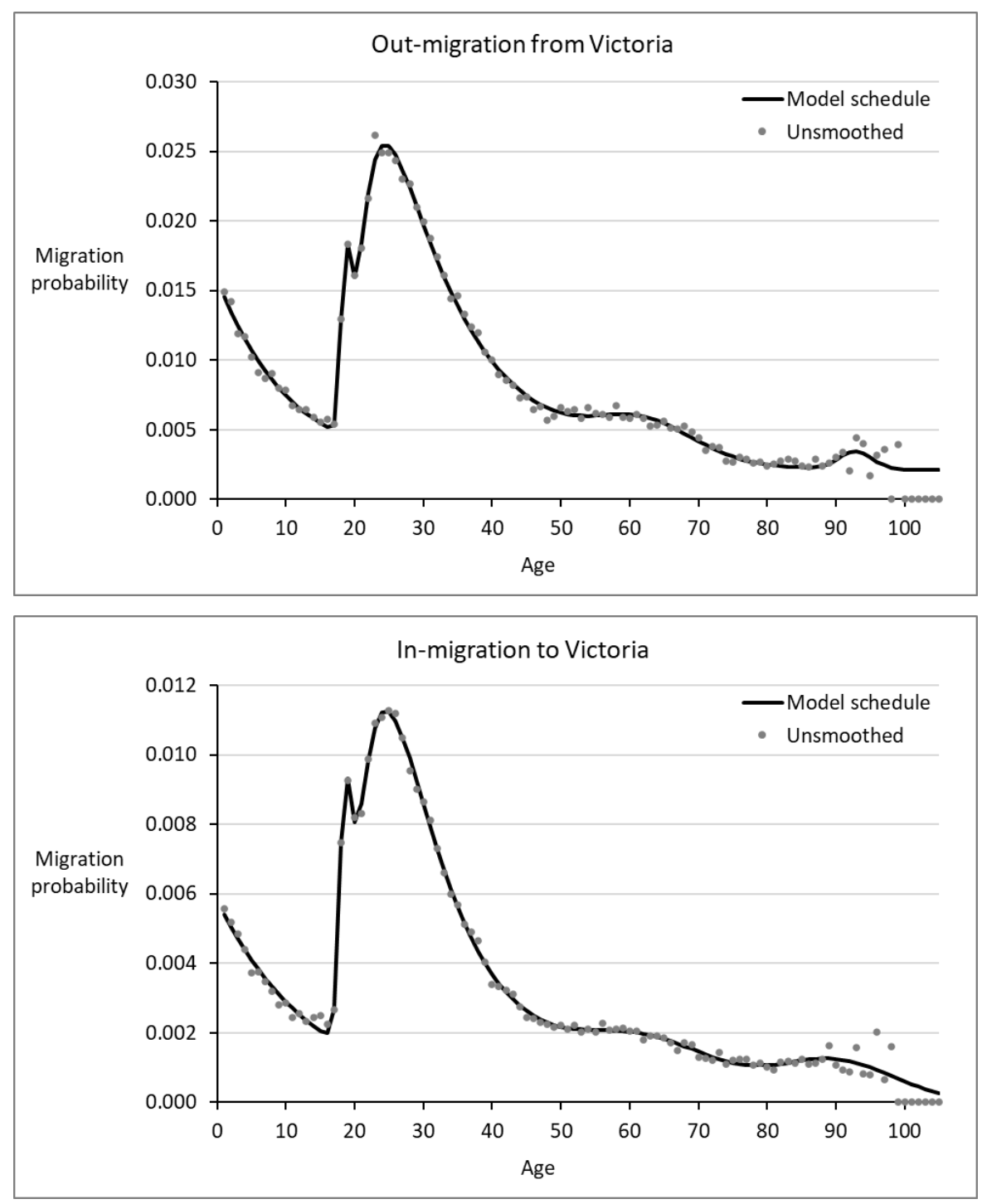

Figure 6 continued 

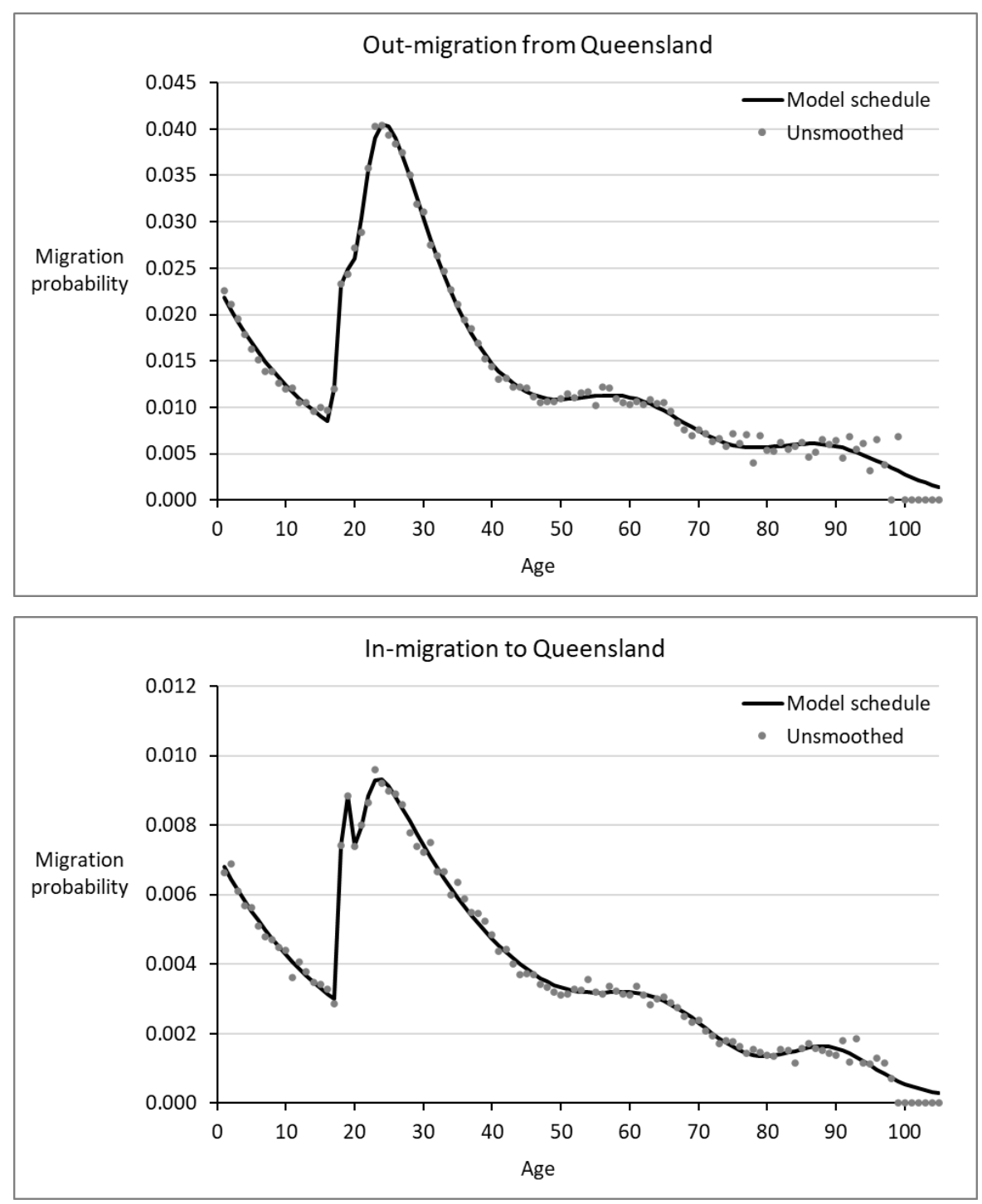

Figure 6 continued 


\section{University Library}

\section{- M M I N E R VA A gateway to Melbourne's research publications}

Minerva Access is the Institutional Repository of The University of Melbourne

Author/s:

Wilson, $T$

Title:

Modelling Age Patterns of Internal Migration at the Highest Ages

Date:

2020-06-25

Citation:

Wilson, T. (2020). Modelling Age Patterns of Internal Migration at the Highest Ages. Spatial demography, 8 (2), pp.175-192. https://doi.org/10.1007/s40980-020-00062-7.

Persistent Link:

http://hdl.handle.net/11343/251816 